\title{
Enhancing a Sustainable Culture of Scientific Research, Writing and Publication in Nepal
}

\author{
Professor Dr Jay N Shah \\ Patan Hospital, Patan Academy of Health Sciences, Lalitpur, Kathmandu, Nepal \\ Email: drjaywufei@hotmail.com,drjaywufei@gmail.com
}

\begin{abstract}
Prof. Jay Narayan Shah was born on 1961 in the historical city of Janakpur, Nepal. He completed diploma at PuTongHua (1982); and Bachelor medicine/surgery (MBBS) on 1988, and Master Surgery (MS, gen surg, biliary surgery) 1991 from School of medicine, Shanghai Jiaotong University. He served as president of Society of surgeons of Nepal, Gen sec of Nepalese society of gastroenterologist, president of NAME-Nepal association of medical editors, vice president of SAARC surgical care society and other leadership activities beyond operation theater.

He is the Chief editors of Journal Of Patan Academy Of Health Sciences, executive editor of Journal of Nepal Health Research Council etc, editorial board member of Chinese Medical Journal of Chinese medical association, reviewers of various journals. He served as the editor in chief of the Journal of society of surgeon of Nepal (JSSN) for two years (2006 - 2008). He has published over 60 scientific papers. Directly involved skill/ trainings - Basic Surgical Skills (BSS), Primary Trauma Course (PTC), research/writing/publishing in scientific journals. He was a board member of the Internal Management Committee IMC Patan Hospital for two terms, 1998-2004; vice chancellor/president (2013-15) of Patan Academy of Health Science (PAHS www.pahs.edu.np), public not for profit autonomous health science university, Kathmandu, Nepal.He is serving as a Professor of surgery, at Patan Hospital, tertiary care teaching hospital of health science university, 'Patan Academy of Health Sciences' (www.pahs. edu.np), Kathmandu, Nepal managing and leading the team as unit in-charge of surgery department. He is the chief of post-graduate committee, chair of ethical-institutional review committee of PAHS etc.
\end{abstract}

Indeed, there is a dire need of steady growth as well as quality in the areas of the scientific research, writing and publication in Nepal. The Journal of Nepal Medical Association (JNMA) is the first and oldest medical journal published in Nepal since 1963 published by Nepal Medical Association. Scientific research, or rather 'development interventions', has a relatively young history in Nepal, beginning in1951 mainly through partnership between government of Nepal and various NGOs, INGOs.Nepal Health Research Council (NHRC), was formally established in 1991, granted through an act of parliament, is the regulating authority for health research activities in the country. National Guidelines for Ethical Review and subsequently Ethical Review Board (ERB) of NHRC was formed in 2001 to review and approve the research proposals in the country. However, as per the rules of universities and Nepal Medical Council, Nursing Council and so on, the academic degrees, especially the Masters' and above compulsorily requires writing 'thesis' by applying standard research methods and ethical guidelines. For such research activities, the academia has been running their research through Institutional Review Committee
(IRC)/ Institutional Review Board (IRB). The NHRC has been actively facilitating formation of such committees to streamline the research and granting accreditation to IRC in the country when criteria prescribed by the NHRC are fulfilled.

The aim of research and publication remains varied and sometime even quite unclear. It would be unfair to blame all. But, many of those researches approved by the health institutions (medical, dental, nursing and public health) are inferior in qualities that simply seem to fulfill the rigid criteria to obtain academic degrees. Later on, publication mostly serves to achieve promotion in the race of teaching faculty ladder, beginning from lecturer to the professorship. The irony of poor quality of research publication is the lack of formal and robust training on how to conduct a scientific research and writing it for publication in scientific journals'. Though there is mandatory in-built curriculum, appropriate teachers, classes and hands-on training in this field during the academic years is failing or inadequate. The candidates of bachelor and master degrees are not required to write journal articles. Only the doctorate degree candidates are required to produce one article. 
Generally, the duration to complete an undergraduate medical school course in Nepal requires 5.5 to 6 years, and then 3 years to complete postgraduate masters. In total, it is about a decade of training, yet there is not even a week devoted to 'teach and train' how to write and publish scientific journal articles.

In this regard, National Academy of Medical Science (NAMS) and Patan Academy of Health Sciences (PAHS) have introduced mandatory 2-4 days of research methodology workshop. The PAHS is the only institute in the country that requires the postgraduate masters $(\mathrm{MD} /$ MS) to produce 'publishable' article in addition to the thesis work. And for such, there are programs built in to the curriculum to provide trainings on 'how to write and publish journal articles'.

Thus, besides the rigid requirements to produce thesis, the health institutions need to incorporate effective teachings and trainings on 'scientific research, writing and publications' to build and develop sustainable culture of 'research, writing, and publication' for the trainees. In this regard, a group of likeminded medical and public health professionals involved in various journals began providing training for 'authors, reviewers, and editors' in collaboration with various institutions (like NHRC, NMA and others) since 2009. This led to the establishment of Nepal Association of Medical Editors (NAME), a voluntary not-for-profit organization, with enthusiastic input from the founding President Dr. Angel Magar and later since 2016, the Executive Board consists of President Prof. Dr. Jay Narayan Shah, Vice-President Prof. Dr. Arun Neopane, General Secretary Prof. Dr. Ganesh Dangal, Treasurer Prof. Dr. Amit Joshi, and member Prof. Dr. Ram Krishna Dulal, Prof. Dr. Gehanath Baral. The NAME has been conducting 1 to 3 days of trainings for 'authors' including doctors, nurses and allied health science professional within Kathmandu valley and outside. There is also further one day trainings for 'reviewers' and 'editors'. The NAME has conducted over 120 such trainings for 30 to 50 participants in each workshops. And now, we see some impressive results as more of such trainings are being conducted by the groups of earlier trainees themselves. Also, the academic institution like PAHS has now incorporated the requirement for 'publishable article' in addition to thesis in their postgraduate programs. They also have in-built teaching learning programs for research, writing and publication in undergraduate medical school. There is additional 'training workshop' for the interns on 'how to write and publish in scientific journal'. Such programs should be the part of inbuilt curriculum of all health institutions and academia.
At present the output of research activities and publications in the country is impossible to trace because of lack of a national registry - a central repository and standard database. The Nepal Journal Online (NepJol) is a repository of journals published from Nepal. It was started by International Network for the Availability of Scientific Publications (INASP) and now it is managed by Tribhuvan University Central Library (TUCL). We academic fraternity plea the government of Nepal to facilitate for a functional repository database. This database will bring all the scientific researches and publications in one standard system. The repository will archive and minimize the duplication as well as redundancy. The research and publication misconducts (like plagiarism) will also be addressed. Accordingly, this may be developed as a national indexing system, such as NepMed, by setting up a minimum standard for journals and its publication quality. This will improve the overall research, writing and publication in the country and also aid to the planning and implementation of health strategies of the government in order to improve the overall health, health education and services.

\section{References}

1. Nepal Association of Medical Editors, NAME. Http:// name.org.np/

2. Nepal Journals Online, NepJol. Https://www.nepjol. info/

3. Patan Academy of Health Sciences, PAHS. http:// www.pahs.edu.np/

4. Sharma JR, Khatri R, Harper I. Understanding Health Research Ethics in Nepal. Developing world bioethics. 2016 Dec 1;16(3):140-7. doi: 10.1111/dewb.12109, PMID: 26841370

5. Nepal Health Research Council, NHRC. Http://nhrc. gov.np/

6. National Academy of Medical Sciences, NAMS. Http://nams.org.np/ 